\title{
The Relationship between Coronary Collateral Circulation and Neutrophil/Lymphocyte Ratio in Patients with Coronary Chronic Total Occlusion
}

\author{
Alper Bugra Nacar ${ }^{a} \quad$ Ali Erayman $^{\mathrm{a}} \quad$ Mustafa Kurt $^{\mathrm{a}}$ Eyup Buyukkaya ${ }^{\mathrm{a}}$ \\ Mehmet Fatih Karakaş ${ }^{a}$ Adnan Burak Akcay ${ }^{a}$ Sule Buyukkaya ${ }^{b}$ Nihat Sen ${ }^{a}$ \\ ${ }^{a}$ Department of Cardiology, School of Medicine, Mustafa Kemal University, and ${ }^{\mathrm{b}}$ Department of Cardiology, \\ Antakya State Hospital, Hatay, Turkey
}

\section{Key Words}

Neutrophil/lymphocyte ratio · Coronary collateral

circulation $\cdot$ Chronic total occlusion

\begin{abstract}
Objectives: To investigate the relationship between neutrophil/lymphocyte ratio (NLR) and coronary collateral circulation (CCC) in patients with coronary chronic total occlusion. Subjects and Methods: Our study population consisted of 275 consecutive patients with chronic total occlusion. One hundred and thirty-eight patients with chronic total occlusion were included in the study. They were classified into 2 groups as follows: impaired CCC (group 1: Rentrop grades 0-1) and good CCC (group 2: Rentrop grades 2-3). The NLR was calculated from the complete blood count. $R e-$ sults: The NLR values of the patients with impaired CCC ( 4.5 \pm 0.7 ) were significantly higher than of those with good CCC $(2.7 \pm 0.6, p<0.001)$. In the multivariate logistic regression test, NLR (OR 33.36, 95\% Cl 8.189-135.7, p < 0.001), highsensitivity C-reactive protein (hs-CRP; OR $2.152,95 \% \mathrm{Cl}$ 1.226-3.777, $p=0.008$ ), estimated glomerular filtration rate (OR 1.167, 95\% Cl 1.049-1.298, $\mathrm{p}=0.004$ ) and systolic blood pressure (OR 1.068, 95\% Cl 1.009-1.1310, $\mathrm{p}=0.025$ ) were independent predictors of impaired CCC. The NLR value $>3.55$ yielded an area under the curve value of 0.957 (95\%
\end{abstract}

$\mathrm{Cl} 0.921-0.992, \mathrm{p}<0.001)$ and demonstrated a sensitivity of $95 \%$ and a specificity of $90 \%$ for the prediction of CCC. A moderate correlation between NLR and hs-CRP was observed $(r=0.443 ; p<0.001)$. Conclusion: Our findings reveal that NLR correlates with the impaired development of coronary collaterals.

(c) 2014 S. Karger AG, Basel

\section{Introduction}

Coronary collateral circulation (CCC) is the adaptation of the heart to ischemia, which develops in order to maintain tissue perfusion [1]. In normal individuals, coronary collaterals exist between the large coronary arteries, but these cannot be visualized on coronary angiography because they carry an insignificant volume of blood $[2,3]$. It is generally accepted that their active functioning is directly linked to the occurrence of severe and recurrent ischemia, but some studies indicate that other factors may also influence their development. Impaired development of collaterals resulting from the increase in acutephase reactants, e.g. C-reactive protein (CRP), indicates the role of inflammation in this process [4].

It is well known that leukocyte activation occurs during an inflammatory reaction. Moreover, leukocytes are in-

\begin{tabular}{ll}
\hline KARGER 125/s & $\begin{array}{l}\text { () 2014 S. Karger AG, Basel } \\
1011-7571 / 14 / 0241-0065 \$ 39.50 / 0 \quad \text { Karger }\end{array}$ \\
$\begin{array}{l}\text { E-Mail karger@karger.com } \\
\text { www.karger.com/mpp }\end{array}$ & $\begin{array}{l}\text { This is an Open Access article licensed under the terms of the } \\
\text { Creative Commons Attribution-NonCommercial 3.0 Un- } \\
\text { ported license (CC BY-NC) (www.karger.com/OA-license), } \\
\text { applicable to the online version of the article only. Distribu- } \\
\text { tion permitted for non-commercial purposes only. }\end{array}$
\end{tabular}

Mustafa Kurt

Mustafa Kemal Üniversitesi Arastirma Hastanesi

Kardiyoloji A.B.D.

TR-31001 Hatay (Turkey)

E-Mail drmustafakurt@yahoo.com 
volved in atherogenesis and thrombus formation. Along with a high number of leukocytes, there is a significant relationship between the neutrophil/lymphocyte ratio (NLR) and the severity and prognosis of cardiovascular disease [5]. To date, the relationship between NLR and CCC in patients with chronic total occlusion has not been investigated. Our aim was to investigate this relationship.

\section{Subjects and Methods}

\section{Study Population}

The study was approved by the Institutional Ethics Committee, and all patients signed an informed consent form. Four hundred and seventy-five patients with stable angina pectoris, with objective signs of ischemia, underwent coronary angiography at the State Hospital in Hatay, Turkey. Patients were excluded who had a coronary angiogram showing a lesion of $<100 \%$ diameter $(\mathrm{n}=$ $266)$, active and ongoing infection $(n=12)$, chronic inflammatory disease $(n=4)$ or a history of percutaneous coronary intervention $(n=37)$ or coronary artery bypass grafting $(n=18)$. Hence, 138 patients (78 males and 60 females) were included in the study.

The clinical risk factors of the patients, such as age, gender, hypertension, diabetes, a history of hyperlipidemia, smoking status and family history, were noted. Furthermore, upon admission, each patient was evaluated for blood pressure (BP), heart rate, previously used drugs, the presence of preinfarction angina, high-sensitivity (hs)-CRP, serum creatinine, blood glucose, lipid profile and hematologic indices. Prior to the coronary angiography, each patient underwent transthoracic echocardiography using the biplane Simpson's method, and left ventricular ejection fraction (LVEF) was measured. Hematologic indices, such as levels of hemoglobin, white blood cells, neutrophils and lymphocytes as well as mean platelet volume and platelet counts, were measured as part of the automated complete blood count using a Coulter LH 780 Hematology Analyzer (Beckman Coulter Ireland Inc., Galway, Ireland). Hypertension was defined as a systolic pressure $>140 \mathrm{~mm} \mathrm{Hg}$ and/or a diastolic pressure $>90 \mathrm{~mm} \mathrm{Hg}$ on at least 2 occasions, or if the individual was on antihypertensive medication. The diagnosis of diabetes mellitus was based on a previous history of diabetes treated with or without drug therapies. The estimated glomerular filtration rate (eGFR) was calculated from serum creatinine using the Modification of Diet in Renal Disease Study equation.

\section{Coronary Angiography}

Quantitative coronary angiography was performed using the standard Judkins technique via the transfemoral route. Coronary chronic total occlusion is characterized by a heavy burden of atherosclerotic plaque, resulting in complete occlusion of the artery for $>3$ months [6]. CCC was graded according to the Rentrop classification [7] as follows: grade $0=$ no filling, grade $1=$ filling of side branches via collateral channels without visualization of the epicardial segment, grade 2 = partial filling of the epicardial major coronary artery via collateral channels, and grade $3=$ complete filling of the epicardial major coronary artery. In patients with more than one coronary lesion, when there was more than one coronary collateral, the one with the highest Rentrop grade was used. The patients were classified into 2 groups: those with impaired CCC (group 1: Rentrop
Table 1. Baseline characteristics according to CCC

\begin{tabular}{|c|c|c|c|}
\hline Variables & $\begin{array}{l}\text { Group } 1 \\
(\mathrm{n}=66)\end{array}$ & $\begin{array}{l}\text { Group } 2 \\
(\mathrm{n}=72)\end{array}$ & $\begin{array}{l}\mathrm{p} \\
\text { value }\end{array}$ \\
\hline Age, years & $60 \pm 9.2$ & $59.6 \pm 7.4$ & 0.760 \\
\hline Male, \% & 52.6 & 61.7 & 0.285 \\
\hline Diabetes, \% & 35 & 16.7 & 0.013 \\
\hline Hypertension & 38.3 & 20.5 & 0.021 \\
\hline Smoking, \% & 20.5 & 18.3 & 0.749 \\
\hline Family history of CAD, \% & 21.8 & 18.3 & 0.616 \\
\hline Systolic BP, mm Hg & $152 \pm 19$ & $143 \pm 15$ & 0.001 \\
\hline Diastolic BP, mm Hg & $84 \pm 10$ & $83 \pm 14$ & 0.833 \\
\hline LVEF, \% & $42.6 \pm 7$ & $48.1 \pm 7.8$ & $<0.001$ \\
\hline WBC count, $\times 10^{3} / \mu \mathrm{l}$ & $9.5 \pm 3.7$ & $9 \pm 3.1$ & 0.532 \\
\hline Platelet count, $\times 10^{3} / \mu \mathrm{l}$ & $255 \pm 78$ & $270 \pm 88$ & 0.339 \\
\hline Mean platelet volume, fl & $8.1 \pm 1.0$ & $8.0 \pm 1.2$ & 0.821 \\
\hline NLR & $4.5 \pm 0.7$ & $2.7 \pm 0.6$ & $<0.001$ \\
\hline Blood glucose, mg/dl & $145 \pm 64$ & $149 \pm 69$ & 0.735 \\
\hline $\mathrm{eGFR}, \mathrm{ml} / \mathrm{min} / 1.73 \mathrm{~m}^{2}$ & $80.8 \pm 6.5$ & $89.9 \pm 9.9$ & $<0.001$ \\
\hline LDL-cholesterol, mg/dl & $123 \pm 29$ & $120 \pm 34$ & 0.581 \\
\hline HDL-cholesterol, mg/dl & $36 \pm 9$ & $37 \pm 7$ & 0.703 \\
\hline Triglyceride, mg/dl & $155 \pm 40$ & $150 \pm 48$ & 0.123 \\
\hline hs-CRP, mg/l & $4 \pm 1.9$ & $3 \pm 1.3$ & 0.001 \\
\hline \multicolumn{4}{|l|}{ Previous medications } \\
\hline Aspirin & 26.9 & 35 & 0.307 \\
\hline Statins & 23.1 & 21.7 & 0.844 \\
\hline ACE inhibitors/ARB & 32.1 & 35 & 0.716 \\
\hline Beta-blockers & 33.3 & 30 & 0.677 \\
\hline Calcium-channel blockers & 25.6 & 18.3 & 0.308 \\
\hline Multivessel disease & 50 & 46.7 & 0.698 \\
\hline
\end{tabular}

$\mathrm{ACE}=$ Angiotensin-converting enzyme; $\mathrm{ARB}=$ angiotensin receptor blocker; $\mathrm{CAD}=$ coronary artery disease; $\mathrm{HDL}=$ high-density lipoprotein; $\mathrm{LDL}=$ low-density lipoprotein; $\mathrm{WBC}=$ white blood cell.

grades $0-1 ; \mathrm{n}=66$ ) or those with good CCC (group 2: Rentrop grades $2-3 ; n=72$ ). Multivessel disease was defined as the presence of a lesion in two or more major epicardial arteries.

\section{Statistical Analysis}

Continuous variables are expressed as a mean \pm standard deviation, whereas categorical variables are expressed as a percentage. Comparisons between the 2 groups were made by using the Student $t$ test, the Mann-Whitney U test or the $\chi^{2}$ test, as appropriate. Comparisons between Rentrop grades were made using the analysis of variance, and the Tukey HSD test was chosen as a post hoc test. Multiple logistic regression analysis was performed to identify the independent predictors of CCC using variables showing marginal association with it on univariate testing $(\mathrm{p}<0.10)$. Receiver operating characteristic (ROC) analysis was used to detect the cutoff value of NLR in the prediction of CCC. Correlation analysis between variables was performed using the Pearson or the Spearman correlation. A p value of $<0.05$ was considered significant. All statistical analyses were carried out using SPSS 17.0 for Windows (SPSS Inc., Chicago, Ill., USA).
Nacar/Erayman/Kurt/Buyukkaya/ Karakaş/Akcay/Buyukkaya/Sen 


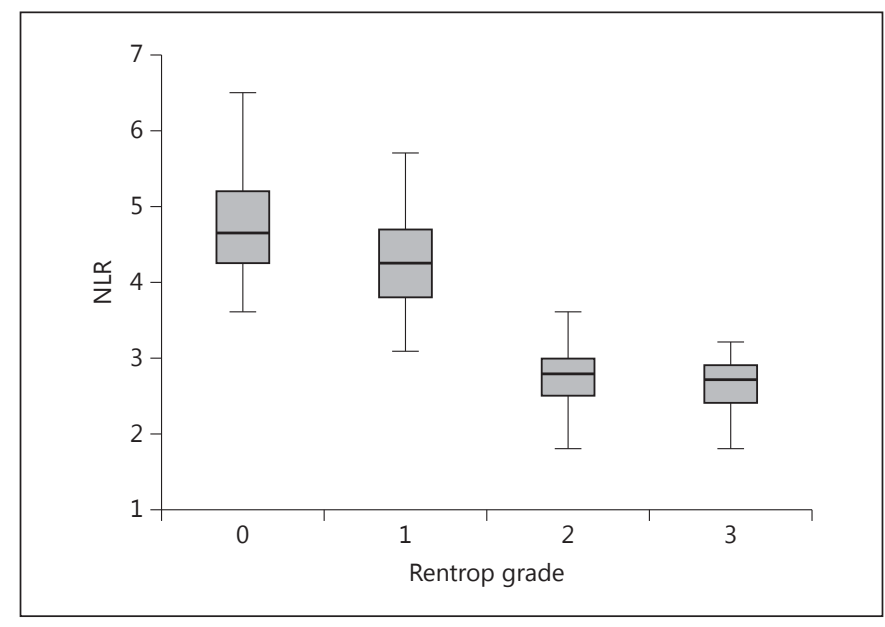

Fig. 1. NLR values according to Rentrop grades.

\section{Results}

The mean age of 138 patients with chronic total occlusion was $59.8 \pm 8.4$ years (range 38-74). A comparison of group 1 and group 2 relative to baseline characteristics is shown in table 1. Patients with impaired CCC exhibited a higher frequency of diabetes, hypertension, systolic BP, NLR and hs-CRP as well as a lower eGFR and LVEF than patients with good CCC. Fasting blood glucose levels $(145 \pm 64$ vs. $149 \pm 69 \mathrm{mg} / \mathrm{dl})$ and mean platelet volumes $(8.1 \pm 1.0$ vs. $8.0 \pm 1.2 \mathrm{fl})$ were comparable between the groups.

The patients with impaired CCC manifested significantly higher NLR values than those with good CCC (4.5 \pm 0.7 vs. $2.7 \pm 0.6, p<0.001)$. While these values were lower in Rentrop grade 1 patients than in grade 0 patients ( $4.3 \pm 0.7$ vs. $4.7 \pm 0.7, p=0.019)$, there was no difference between Rentrop grade 2 and grade 3 patients $(2.7 \pm 0.5$ vs. $2.8 \pm 0.6, \mathrm{p}=0.901$; fig. 1 ).

Univariate analysis found the following variables to be significant: age, sex, diabetes, hs-CRP, NLR, eGFR, systolic BP and LVEF. The multivariate logistic regression analysis showed that NLR (OR 33.36, 95\% CI 8.189-135.7, $\mathrm{p}<0.001$ ) and systolic BP (OR 1.068, 95\% CI 1.009-1.131, $\mathrm{p}=0.024)$ were independent predictors of impaired CCC (table 2). Discriminative accuracy of the analysis without including NLR (-2 log likelihood: 129.2, Cox and Snell $\mathrm{R}^{2}$ : 0.351 and Nagelkerke's $\left.R^{2}: 0.471\right)$ was significantly lower when compared to the analysis with incorporation of the NLR (-2 log likelihood: 49.9, Cox and Snell $R^{2}: 0.635$ and Nagelkerke's $R^{2}$ : 0.851). ROC curve analysis was performed to detect the best cutoff value of the NLR in the

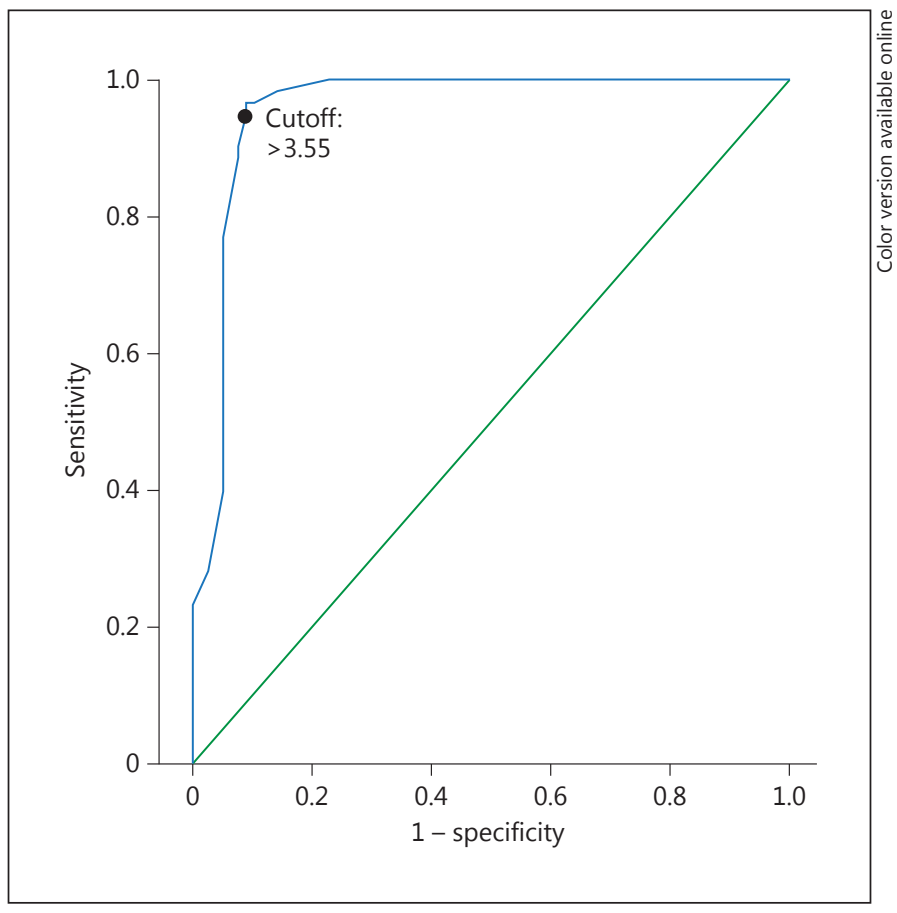

Fig. 2. ROC curve for NLR values: green line = reference line, blue line $=$ NLR values.

prediction of impaired CCC. An NLR value of $>3.55$ yielded an area under the curve value of 0.957 (95\% CI $0.921-$ $0.992, \mathrm{p}<0.001)$ and demonstrated a sensitivity of $95 \%$ and a specificity of $90 \%$ for the prediction of CCC (fig. 2). Correlation analysis revealed a moderate correlation between NLR and hs-CRP ( $\mathrm{r}=0.443 ; \mathrm{p}<0.001)$.

\section{Discussion}

Our findings revealed that a higher NLR was associated with impaired CCC. The small vascular structures between the epicardial coronary arteries in a normal human heart cannot be visualized on normal angiography due to the very small volume of blood flowing inside them $[2,3]$. However, the development of a stenosis in the epicardial coronary arteries leading to ischemia causes a pressure gradient within the collaterals which increases the blood flow within the collateral arteries and, consequently, the collaterals may become visible on angiography [8]. The development of CCC occurs as a result of angiogenesis (new vessel formation) and/or arteriogenesis (the growth of preexisting arterioles) [9]. Many factors may affect the development of CCC, such as the severity/ rate of progression of coronary stenosis, diabetes, hyper- 
Table 2. Multivariate logistic regression analysis to detect the independent predictors of impaired coronary collateral circulation

\begin{tabular}{llllr}
\hline Variables & $\begin{array}{l}\text { Univariate OR } \\
(95 \% \text { CI })\end{array}$ & $\begin{array}{l}\text { Univariate } \\
\text { p value }\end{array}$ & $\begin{array}{l}\text { Multivariate OR } \\
(95 \% \text { CI })\end{array}$ & $\begin{array}{l}\text { Multivariate } \\
\text { p value }\end{array}$ \\
\hline Age & $0.994(0.955-1.034)$ & 0.760 & $1.083(0.948-1.237)$ & 0.242 \\
Sex & $0.689(0.374-1.310)$ & 0.285 & $0.804(0.146-4.439)$ & 0.803 \\
Diabetes & $2.692(1.213-5.977)$ & 0.013 & $0.620(0.072-5.135)$ & 0.662 \\
Hypertension & $2.409(1.130-5.135)$ & 0.021 & $0.654(0.089-4.795)$ & 0.676 \\
LVEF & $0.906(0.860-0.954)$ & $<0.001$ & $0.943(0.823-1.081)$ & 0.401 \\
Systolic BP & $1.034(1.012-1.056)$ & 0.001 & $1.068(1.009-1.131)$ & 0.024 \\
NLR & $24.19(8.915-65.65)$ & $<0.001$ & $33.36(8.189-135.7)$ & $<0.001$ \\
eGFR & $0.923(0.880-0.967)$ & $<0.001$ & $0.967(0.897-1.041)$ & 0.371 \\
hs-CRP & $1.795(1.346-2.393)$ & 0.001 & $1.946(0.861-4.397)$ & 0.110 \\
\hline
\end{tabular}

tension, smoking status, endothelial dysfunction, exercise, endogenous mediators, oxidative stress and certain drugs [10]. The development of CCC in acute coronary syndromes has been shown to be associated with a better myocardial perfusion and ventricular function as well as a lower incidence of adverse cardiovascular events in the long term [11-13]. During CCC development, many endogenous mediators such as growth factors, vascular endothelial growth factor, nitric oxide and inflammatory and neurohumoral markers are involved along with endothelial dysfunction. Moreover, proinflammatory enzymes and cytokines secreted from the inflammatory cells are considered to play a role in the development of collaterals. CRP was demonstrated to inhibit the production of nitric oxide and angiogenesis [14].

NLRs calculated from leukocyte subtypes have been accepted as being markers of inflammation in cardiovascular diseases [5]. Neutrophils are the first elements of inflammation in the injured myocardium and they play a major role in thrombotic and inflammatory processes. They are involved in the inflammatory response (when a significant increase in their numbers is observed) while lymphocytes play a role in the specific immune response. A correlation has been shown between the neutrophil count and reduced ejection fraction and infarction expansion [15]. It has been suggested that the decreased lymphocyte count in inflammation might be related to the increased level of steroids (cortisol) in relation to stress and increased apoptosis [16]. A decreased lymphocyte count indicates a poor outcome in acute coronary syndrome $[17,18]$. The NLR is considered more effective than the leukocyte count in predicting increased cardiovascular risk [5]. Horne et al. [5] reported that while white blood cell count is an independent predictor of death/ myocardial infarction, NLR has a greater predictive value. Many studies have shown that inflammation plays a major role in both the initial phase and the progression of atherosclerosis $[19,20]$. A link between inflammatory cytokines and collateral development has been discovered [9]. Along with endothelial dysfunction, cytokines such as TNF- $\alpha$ and IL- 6 have been found to be predictors of poor collateral development. Moreover, many studies show that higher hs-CRP concentrations are associated with insufficient CCC development $[21,22]$. Our findings confirm these observations. Whether it is the cause or the effect, NLR is associated with impaired development of CCC in chronic total occlusion patients. This suggests that the determination of NLR might be helpful in the detection of high-risk patients.

The limitations of this study include the relatively small sample size and the lack of data on other plasma markers involved in the pathophysiology of impaired CCC, such as vascular endothelial growth factor, nitric oxide and TNF- $\alpha$. In addition, this was a cross-sectional study, so no follow-up was conducted.

\section{Conclusion}

This study has shown that a high NLR was associated with impaired CCC in patients with coronary chronic total occlusion. Further studies are needed to investigate the cause and effect relationship between NLR and CCC.

\section{Disclosure Statement}

The authors have no conflicts of interest to declare.
Nacar/Erayman/Kurt/Buyukkaya/ Karakaş/Akcay/Buyukkaya/Sen 


\section{References}

1 Fujita M, Sasayama S, Ohno A, et al: Importance of angina for development of collateral circulation. Br Heart J 1987;57:139-143.

$>2$ Levin DC: Pathways and functional significance of the coronary collateral circulation. Circulation 1974;50:831-837.

3 Elayda MA, Mathur VS, Hall RJ, et al: Collateral circulation in coronary artery disease. Am J Cardiol 1985;55:58-60.

-4 Gulec S, Ozdemir AO, Maradit-Kremers H, et al: Elevated levels of C-reactive protein are associated with impaired coronary collateral development. Eur J Clin Invest 2006;36:369375.

$\checkmark 5$ Horne BD, Anderson JL, John JM, et al: Which white blood cell subtypes predict increased cardiovascular risk? J Am Coll Cardiol 2005;45:1638-1643.

-6 Stone GW, Kandzari DE, Mehran R, et al: Percutaneous recanalization of chronically occluded coronary arteries: a consensus document. Part I. Circulation 2005;112:23642372.

7 Rentrop KP, Thornton JC, Feit F, et al: Determinants and protective potential of coronary arterial collaterals as assessed by an angioplasty model. Am J Cardiol 1988;61:677-684.
-8 Newman PE: The coronary collateral circulation: determinants and functional significance in ischemic heart disease. Am Heart J 1981;102:431-445.

-9 Seiler C: The Collateral Circulation of the Heart. London, Springer, 2009.

$>10$ Seiler C: The human coronary collateral circulation. Eur J Clin Invest 2010;40:465-476.

-11 McMurtry MS, Lewin AM, Knudtson ML, et al: The clinical profile and outcomes associated with coronary collaterals in patients with coronary artery disease. Can J Cardiol 2011; 27:581-588.

12 Ilia R, Wolak A, Amit G, et al: Collateral blood flow can predict myocardial blush grade in primary coronary intervention. Catheter Cardiovasc Interv 2012;80:67-70.

13 Nathoe HM, Koerselman J, Buskens E, et al: Determinants and prognostic significance of collaterals in patients undergoing coronary revascularization. Am J Cardiol 2006;98:31-35

14 Verma S, Wang CH, Li SH, et al: A self-fulfilling prophecy: C-reactive protein attenuates nitric oxide production and inhibits angiogenesis. Circulation 2002;106:913-919.

15 Kirtane AJ, Bui A, Murphy SA, et al: Association of peripheral neutrophilia with adverse angiographic outcomes in ST-elevation myocardial infarction. Am J Cardiol 2004;93:532536.
16 Hotchkiss RS, Karl IE: The pathophysiology and treatment of sepsis. N Engl J Med 2003; 348:138-150.

17 Ommen SR, Gibbons RJ, Hodge DO, et al: Usefulness of the lymphocyte concentration as a prognostic marker in coronary artery disease. Am J Cardiol 1997;79:812-814.

18 Blum A, Sclarovsky S, Rehavia E, et al: Levels of T-lymphocyte subpopulations, interleukin-1 beta, and soluble interleukin-2 receptor in acute myocardial infarction. Am Heart J 1994;127:1226-1230.

19 Weissberg PL, Bennett MR: Atherosclerosis an inflammatory disease. N Engl J Med 1999; 340:1928-1929.

20 Osiecki H: The role of chronic inflammation in cardiovascular disease and its regulation by nutrients. Altern Med Rev 2004;9:32-53.

21 Kerner A, Gruberg L, Goldberg A, et al: Relation of C-reactive protein to coronary collaterals in patients with stable angina pectoris and coronary artery disease. Am J Cardiol 2007;99:509-512.

22 Veselka J, Prochazkova S, Duchonova R, et al: Relationship of C-reactive protein to presence and severity of coronary atherosclerosis in patients with stable angina pectoris or a pathological exercise test. Coron Artery Dis 2002; 13:151-154. 